\title{
IDENTIFICATION AND SYMBOLIZATION IN ADOLESCENT DEPRESSION TODAY
}

\author{
Larissa Leão de Castro, \& Terezinha de Camargo Viana \\ Postgraduate program in Clinical Psychology and Culture, University of Brasilia (Brazil)
}

\begin{abstract}
This theoretical study, of a qualitative character, proposes to investigate what the relationship between identification and symbolization is in adolescent depression today. The importance of discussing the theme is as a direct result of the alarming observation that, as an illness of epidemic proportions, it does not refer to a natural illness, whose origin is restricted to the individual level, but mainly refers to structural determinations present in society. In this sense, this work addresses the problem of understanding which identification and symbolization processes are present in a culture that has transformed depression among adolescents into a social symptom. In order to develop this, it expresses the main determinations that are present at puberty, discussing the processes of primary and secondary narcissism, the nature of identifications, mechanisms of the capitalist culture of consumption and its relationship with the processes of subjectivation, reflecting on the possibilities and obstacles of the social bond to offer and / or allow symbolization of anxieties and humanizing psychical work.
\end{abstract}

Keywords: Identification, adolescence, symbolization, depression, social symptoms.

\section{Introduction}

This study aims to investigate the relationship between identification, narcissism and symbolization in adolescent depressions today. We note the importance of moving forward in the study of the theme, considering the predicted trend that in 2020 depression would be the second cause of morbidity in the world (Kehl, 2009). This is in addition to the alarming data taken up by Dolto (1990) that for 20 years the second leading cause of death among adolescents in the United States has been suicide. This is something that has been ignored and, as a rule, has been shadowing the adolescent and is often associated with the mechanisms of the problem of depression.

\section{The capitalist culture of consumption, narcissistic fragility, identifications and acting out}

In the text Adolescence: act and actuality, Bianca Savietto and Marta Cardoso (2006) analyze the route to the act as a resource increasingly used by adolescents, reinstating the question of the relationship between subjectivity and culture. To do this, the authors discuss the determinations considered central for the constitution of the phenomenon, such as helplessness, identifications, narcissistic fragility, the current context of the West that propagates this form of subjectivity and the meaning of the recourse to the act in this context. These elements can be deepened to better understand the relationship between the depressive symptoms and the structure of this consumerist culture.

The authors start from the psychoanalytical definition of adolescence, referencing both the biological dimension of puberty - which includes the novelty of the unification of the drives under genital primacy -, as well as the unconscious implications of this experience in the pulsional dynamics, requiring psychical work to address the representation and the symbolization of that period in which there is pulsational excitation changes. This demands the work of reorganizing body, sexual and psychic identity, as it is understood from Marty's description. (Cardoso, Savietto, 2006).

The importance of the analysis of narcissism in this period is recovered, since to it belongs the function of exercising the self-preservation of the image of the unifying Ego. In this stage of life, this function is under attack, since there are major transformations in the body that the subject has to deal with, in addition to requiring a gradual disconnection from the parental figures that supported the internal structuring of the Ego-Ideal, in the constitution of primary narcissism. It must be weakened, together with the omnipotence that was associated with these figures, to make room for another process of subjectification through the internalization and consolidation of other identifying references that will internally form the subject's Ideal of the Ego, consolidating the structuring of secondary narcissism. For this reason, the authors claim that it is essential to reduce the level of narcissism to make room for a new subjective reorganization. (Cardoso, Savietto, 2006). 
However, their analysis argues that for this process to occur, the presence of "a significant narcissistic preamble" is necessary (Cardoso, Savietto, 2006, p.21) for the psychic restructuring through the identificatory trajectory. They rely on the work of Marty when he emphasizes that one of the elements of the failure of this transition is the lack of support from parents or whoever represents them (Cardoso, Savietto, 2006, p.21).

At the same time, for the predominance of the Ego-Ideal to cease to operate and give space for subjectification by the Ideal of the Ego, some work needs to be done in the area of culture. As pointed out by Pinheiro (2001), culture and its mediations must offer objects, identifying references that weaken totalizing omnipotence, since the individual at that moment feels threatened in his integrity by helplessness, always using the other as a model to construct himself. (Cardoso, Savietto, 2006).

Just like the concept of drive, the notion of helplessness encompasses both a biological and a psychic dimension. It concerns a psychomotor insufficiency and the psychic apparatus of symbolizing and representing the amount of pulsational excitation that the subject is unable to master. Added to this factor, the authors' analysis that the strength of Western culture is not found in the power of symbolization, which makes the move towards the suicidal act more understandable as a resource used in adolescence in this historical particularity. (Cardoso, Savietto, 2006).

In this sense, they highlight some elements. Among them, the Winnicottian analysis of the increasing presence of a depression in the parents, which does not allow the constitution of an identifying reference that life in itself, is worth it. If this base of primary narcissism is already weakened, it becomes even more difficult to move through secondary narcissism and the internal construction of the Ideal of the Ego. As such, we recognize that western culture has a tendency to move towards a state of helplessness in general, especially in adolescence, when this issue is updated. In other words, there is a weakening of the mediations that culture offers in its power to build symbolic order based on identifying references. (Cardoso, Savietto, 2006).

Among the factors involved in this process, Cardoso and Savietto (2006) highlight the centrality of the cult of the body in the formation of identities. They resume the analysis by Jurandir Costa (2004) that, at other times in the history of Western culture, relationships were based on people's actions, which later led to an emphasis on moral and interior characteristics, while today the relationships are based on the bodily and imagery attributes that the subjects have of themselves. For the author, due to the influence of the media in the new processes of subjectification, these attributes are associated with money, power, success and fame.

As a large part of the population is excluded from this scenario, it seeks to affirm subjectivity at least through a body image that deserves success, seeking to have the same body as famous people have, as well as exposing it uninterruptedly, as in a showcase open to assessments. This raises a problem for adolescents, as they go through a period of great and constant bodily transformations that are beyond the standard of beauty, which, in turn, generates anguish that aggravates the problems already faced. (Cardoso, Savietto, 2006)

With the acquiescence of the media in the processes of subjectivation, the references to fleeting celebrities, expressing the presentification of time (the here-and-now) are now occurring, so the search for fame leads to the absence of commitments to the future, and these fleeting values are always tied to body image. Through this logic of instantaneity, the authors point out the absence of representations of the Ideal of the Ego and, in their place, the presence of narcissistic ideals of completeness and omnipotence in the instantaneous logic that objects for consumption can offer. This factor is intertwined with the loss of lasting authority figures, the absence of intergenerational difference, showing that both parents and children often remain in what is called the generation of adolescents, which makes the processes of subjectification resistant to the dimension of alterity, to difference (Cardoso, Savietto, 2006).

Thus, it is through the understanding of these processes of the current Western culture that Cardoso and Savietto (2006) understand the increasing acting out by the adolescent. We take up Philippe Jeammet's analysis when he interprets that there is a short circuit in the demand for psychical work of symbolization and in its place, an acting out appears. Although the progress to the act expresses the need for a review of the psychological discharge in the face of anguish, an archaic mechanism typical of primary narcissism ensures that the Ego-Ideal predominates over the Ideal of the Ego in the absence of mediations by culture, which make it possible to carry it out. In this sense, thinking about adolescence presupposes not universalizing these conditions of subjectivity, but understanding them circumscribed to the present context of Western culture.

\section{Final considerations: Psychical work $\mathrm{x}$ depression as a social symptom}

As we saw previously, the suicidal act is an effect of the absence of symbolization reinforced by culture, depression is also a symptom that expresses the primary processes of narcissism, as well as the primary nature of the identification processes. This indicates the development of a barrier to this waiting time and of symbolization that would allow the elaboration of anxieties, the reorganization of identifiable 
references, the ability to fantasize, to think about the transformation of their reality, etc. (Kelh, 2009). This waiting time becomes sparse, similar to that which did not allowed the person to meet the demand of the other, in addition to not responding to the imperative of jouissance and not seeking to be a total object. Thus, so many elements of the construction of narcissism are put in place, processes of identification and symbolization typical of the gradual history of the subjects up to the breadth of this structuring present in the culture that is completely conducive to the strengthening of the depressive symptom in the social bond.

In the same sense, the works of Dolto (1990) emphasize the importance of analyzing the mediation of culture when, for example, it investigates the genesis of the problem of suicide among adolescents as an epidemic and not as an isolated issue, that is, it concerns recurrent causalities in the inter-constitutive relationship between individual and culture. In view of the alarming data of young people attempting suicide in the United States, the author questions what factors could be in play and mentions, among them, the discovery of their presence in regions demonstrating accelerated development. This is quite significant within the North American way of life that radicalizes the internalization of capitalism's tendency to produce and be.

If the regions where the problem has assumed greater proportions have a more accelerated level of development, this indicates exactly what has been done about the absence of the necessary waiting time for work on people's psyche which results in the possibility of elaborating and transforming reality. Even with this element in common, on the other hand, there are specificities among the complexity of the reasons in different countries that often lead adolescents to commit suicide.

Having made this journey and then realizing that the absence of work on the psyche (which would allow symbolization, elaboration and transformation of reality), added to the manifestations of the culture of the values and ways of life of capitalism, we note there is a transformation not only in the symptom of suicide, but also in the symptoms of depression as a problem of epidemic proportions.

In this sense, Dolto (1990) points out that any proposal of prevention in the face of the phenomenon - which in the present study can extend to the understanding of the treatment of depression -, it is essential to make the ghost speak, to allow time for work on the psyche. Just as with children, it is desirable to speak more frankly about death to adolescents who are experiencing this problem. It is also important for the adolescent to feel better understood when talking to family members in addition to their parents. If he wants to die, it is important that the psychotherapist asks him about the death wish and what prevents him from going through with it. In this way, ghosts can be talked about, time is allowed for the elaboration of, and transformation of what the adolescent is often silent about. As it is a taboo subject, as with the whole culture around them, the author warns about the effect of the growth of that which it has been silent about and yet has grown into adolescence. (Dolto, 1990).

In this same sense, Maria Rita emphasizes that it is necessary to "allow a rectification of the subject within the (imaginary) family story that gives meaning to the (symbolic) ghost" (Kehl, 2009, p. 231, author's translation). It is necessary to encourage him to overcome his reflected position to allow the possibility of fantasizing, to deal with his desire, which would allow him to deal with what is absent, but not in the sense of a disastrous or tearing apart experience, but as the possibility of sustaining a desire, a fantasy, and the possibility of transformation.

If we live in the culture of capitalism in which the prevailing social bond propagates the imperative of jouissance and indestructible happiness, we note that this is just another guise of the same bourgeois ideal for the free individual to give away his ability to work, produce, and achieve happiness, which in turn is sought indefinitely via consumer objects. Obviously, that same culture propagates the ideology that if the person fails to respond to the mandates to "enjoy", the fault is the individual's. In this sense, the author indicates that in the phenomenon of depression there is a suffering experienced as a catastrophe of unhappiness for not being happy, for not being able to respond to this mandate of the culture of "enjoyment". (Kehl, 2009).

\section{References}

Dolto, F. (1990). Los suicidios de los adolescentes: una epidemia ocultada. In: La causa de los adolescentes. Barcelona: Seix Barral.

Freud, S. (1996). Psicologia de grupo e análise do eu. In: Freud, S. Obras psicológicas completas de Sigmund Freud. Rio de Janeiro: Imago, Vol. 18 (p. 77-154). (Trabalho original publicado em 1921).

Freud, S. (1996). Sobre o narcisismo - uma introdução. In: Freud, S. Obras psicológicas completas de Sigmund Freud. Rio de Janeiro: Imago, Vol. 14 (p. 77-108). (Trabalho original publicado em 1914).

Kehl, M. R. (2009). O tempo e o cão: a atualidade das depressões. São Paulo: Boitempo.

Savietto, Bianca Bergamo, \& Cardoso, Marta Rezende. (2006). Adolescência: ato e atualidade. Revista Mal Estar e Subjetividade, 6(1), 15-43 